\title{
Minimum Data Set of Self-Care Training Software for Epilepsy Patients
}

\author{
Ali Aliabadi ${ }^{1}$, Haleh Farsadhabibi² ${ }^{2}$ Mostafa Langarizadeh ${ }^{3}$, Alireza Khosravi ${ }^{4}$ \\ ${ }^{1}$ Department of Health Information Technology, Paramedics School, Zahedan University of Medical Sciences, \\ Zahedan, Iran. 2, 3 Department of Health Information Management, School of Health Management and \\ Information Sciences, Iran University of Medical Sciences, Tehran, Iran. ${ }^{4}$ Department of Neurology, Clinical \\ Immunology Research Center, Zahedan University of Medical Sciences, Zahedan, Iran.
}

\section{ABSTRACT}

\section{BACKGROUND}

Epileptics mostly suffer from physical, mental and social disorders. So, it is necessary to offer the patients training programs and improve their skills which may prevent a seizure. Minimum Data Set (MDS) is a standard tool to access accurate data and is essential to design self-care training software for epileptics. This study has been done in order to determine MDS necessary for self-care software of epilepsy.

\section{METHODS}

This descriptive study was conducted in the first half of 2020 in cooperation with 23 neurologists. Questionnaire was the research tool. To validate the questionnaire, validity method was applied and its reliability was confirmed through retest method. Data was analysed using SPSS (ver. 21).

\section{RESULTS}

MDS was organised in to five groups: demographic, clinical symptoms, clinical information, medications and reminders, and recommendations. Demographic information includes 9 data elements, clinical symptoms include 23 data elements, medications and reminders had 2 parts and 11 elements and recommendations include 10 elements.

\section{CONCLUSIONS}

Due to importance of data and information in self-care patients suffering from epilepsy, software role in gathering data and sharing it with doctors and also reducing patients attending the hospital, minimum data must be determined. The designed data set can fulfil epileptics' needs, facilitate processes, promote their health and ease the financial burden of caring for patients with chronic illness.
Corresponding Author:

Haleh Farsadhabibi,

Department of Health Information Management, School of Health Management and Information Sciences, Iran University of Medical Sciences, Tehran, Iran,

E-mail: h.farsadhabibi@yahoo.com

DOI: $10.14260 /$ jemds/2021/41

How to Cite This Article:

Aliabadi A, Farsadhabibi H, Langarizadeh $M$, et al. Minimum data set of self-care training software for epilepsy patients. J Evolution Med Dent Sci 2021;10(04):190193, DOI: 10.14260/jemds/2021/41

Submission 01-10-2020,

Peer Review 27-11-2020,

Acceptance 03-12-2020,

Published 25-01-2021.

Copyright $@ 2021$ Ali Aliabadi et al. This is an open access article distributed under Creative Commons Attribution License [Attribution 4.0 International (CC BY 4.0)]

\section{KEY WORDS}

Minimum Data Set, Self-Care, Epilepsy 


\section{BACKGROUND}

Epilepsy is one of the most common neurological diseases and people from all ages, races and places could get affected. ${ }^{1}$ Its symptoms are frequent seizures in which unnatural electrical activities in the brain cause blackout and seizure. Patients are unaware of seizure due to its randomness and it may increase the risk of physical injuries. ${ }^{2}$ People who suffer from this disease are of about 50 to 70 million in all over the world; 3,4 this shows that they include $0.75 \%$ of global burden of disease. ${ }^{5}$ High proportion of epileptics in developing countries and poor epileptics in developed countries remain untreated. Therefore, we need trained medical personnel to detect seizures and monitor the patients' improvement. Unfortunately, demand for neurologists is more than the neurologists introduced to the society. In the US, the studies estimated that demands for neurologists will rise to 21500 in 2025, while the number of neurologists' present will be $18000 .^{6}$

Considering that epileptics suffering from physical, mental and social disorders, it might cause financial difficulties and reduction in quality of life. An opinion poll displayed that, comparing to the United States Census Bureau's norms, these people receive less education, the possibility of their employment is less, and their families makes less money. Controlled experiment with high quality, particularly for nonmedical treatments such as training programs and upskillingwhich may prevent seizures or help patients to sustain seizures better are not available. ${ }^{7}$

Self-care means daily activities in order to decline or control the illness impacts on physical health condition. ${ }^{8}$ Selfcare includes changes in life style, alternative treatments, decrease stresses and medications. ${ }^{9}$ Accordingly, this is an appropriate method to support patients with chronic epilepsy. ${ }^{10,11}$ This method is an inseparable one of all primary and professional health care; therefore, a little facilitating in the process of executing this method can improve whole population's health, economic and social situation. Self-care makes changes in patients' behaviour and understanding 12 and can fulfil lots of their needs and enhance their health. Studies show that care givers e.g. expert physicians and nurses did not attempt enough in training and self-care and this matter should be considered. ${ }^{13}$

Increasing patient's awareness and applying clinical behaviour advises potentially lead to reduce costs, help patients' self-care and indirectly encourage health workers to know more about this disease. Despite having these potential benefits, patients mostly face difficulties in applying clinical behaviour advises in their daily plans that include lack of time and inadequate knowledge and education in advising properly. ${ }^{14}$ Investigation show that information technology (IT) is a powerful factor influencing high performance and efficiency of organisations. That is the reason different industries in order to survive have walked towards using this technology efficiently. Healthcare industry is not an exception and different countries - according to their role and importance of healthcare industry and IT's, direct and indirect impacts on various dimensions of social development considered IT as a tool to develop health information and upgrade healthcare system consequences. ${ }^{15,16}$ Therefore, by creating self-care systems for epileptics the possibility of accessing and responding to clinical needs will be increased.
To design epilepsy self-care training software, determination of minimum standard data set is needed. The aim of this study is to assign minimum data set of epilepsy as a standard tool to accurate data considered as basic needs in designing self-care training software.

\section{METHODS}

This research was a descriptive-applied research carried out from April 2020 to August 2020. Expert physicians and neurology subspecialties who worked in Ali ibn Abi Talib hospital of Zahedan, Imam Reza Hospital of Tabriz and Rasoul Akram Hospital of Tehran were chosen as study population. The study was done with cooperation of 23 neurologists using purposive sampling method. To collect data, questionnaire was used which was designed based on a systematic review study. The content validity of the questionnaires was evaluated using the comments from 3 experts in the fields of health information management and 10 experts in the fields of neurology. To ensure their reliability, the questionnaires were completed by 13 of the aforementioned experts; they were asked to complete the questionnaires for a second time after two weeks. The collected data was analysed using SPSS version 21, and the questionnaire had a Cronbach's alpha of 0.79. The questionnaire includes demographic, clinical symptoms, clinical information, medications and reminders and recommendations. In every item of questionnaire, respondents were asked to determine necessary and unnecessary data elements. The respondents were assured that their response will be saved confidentially and merely will be used along research objectives. Data analysis has been done through descriptive statistics using SPSS version 21. To determine MDS, data elements have been chosen with an average of $65 \%$.

\section{RESULTS}

In this research, data elements were determined according to prior study reviews. Then, MDS was designed based on participants' comments including neurologists and neurosurgeons. Participants' demographic specifications is displayed in Table 1 . Respondents were mostly men and the most people were in the age group of 50 to 60 with more than 15 years' experience.

\begin{tabular}{|c|c|c|c|}
\hline \multicolumn{2}{|c|}{ Characteristics } & Number & Percentage \\
\hline \multirow{3}{*}{ Age } & $<60$ & 7 & 30.4 \\
\hline & $50-60$ & 12 & 52.2 \\
\hline & $>60$ & 4 & 17.4 \\
\hline \multirow{2}{*}{$\begin{array}{c}\text { Work } \\
\text { Experience }\end{array}$} & $5-10$ & 6 & 18.7 \\
\hline & $>10$ & 17 & 81.2 \\
\hline \multirow{2}{*}{ Gender } & Female & 4 & 17.4 \\
\hline & Male & 19 & 82.6 \\
\hline \multicolumn{4}{|c|}{$\begin{array}{c}\text { Table 1. Frequency and Percentage of Participants' } \\
\text { Demographic Characteristics }\end{array}$} \\
\hline
\end{tabular}

MDS was organised in five groups including demographic, clinical symptoms, clinical information, medications and reminders and recommendations. Total number of collected data elements was 73 (15 elements for demographic, 24 
elements for clinical symptoms, 9 elements for clinical information, 24 elements for medications and reminders, and 11 elements for recommendations) which was reduced after expert panel discussion (Tables 2 to 4 ).

\begin{tabular}{|c|c|c|c|c|c|}
\hline Theme & Data Elements & $\begin{array}{r}\text { Nece } \\
\text { Number }\end{array}$ & $\begin{array}{l}\text { sary } \\
\text { Percent }\end{array}$ & $\begin{array}{l}\text { Unnece } \\
\text { Number }\end{array}$ & $\begin{array}{l}\text { essary } \\
\text { Percent }\end{array}$ \\
\hline \multirow{15}{*}{ Demographic } & $\begin{array}{l}\text { First name and last } \\
\text { name }\end{array}$ & 23 & 100 & 0 & 0 \\
\hline & National code & 23 & 100 & 0 & 0 \\
\hline & Gender & 23 & 100 & 0 & 0 \\
\hline & Age & 23 & 100 & 0 & 0 \\
\hline & Weight & 20 & 87 & 3 & 13 \\
\hline & Citizenship & 17 & 73 & 6 & 27 \\
\hline & Residence address & 5 & 21.7 & 18 & 78.3 \\
\hline & Phone number & 8 & 34.7 & 15 & 65.3 \\
\hline & Height & 16 & 69 & 7 & 31 \\
\hline & Number of children & 20 & 87 & 3 & 13 \\
\hline & Job & 18 & 78.5 & 5 & 21 \\
\hline & Education & 15 & 65.3 & 8 & 34.7 \\
\hline & Marital status & 19 & 83 & 4 & 17 \\
\hline & Father's name & 3 & 13 & 20 & 87 \\
\hline & Mother's name & 0 & 0 & 23 & 100 \\
\hline \multicolumn{6}{|c|}{$\begin{array}{l}\text { Table 2. Condition of Demographic MDS } \\
\text { from Neurologists' Point of View }\end{array}$} \\
\hline
\end{tabular}

\begin{tabular}{|c|c|c|c|c|c|}
\hline \multirow[b]{2}{*}{ Scope } & \multirow[b]{2}{*}{ Data Elements } & \multicolumn{2}{|c|}{ Necessary } & \multicolumn{2}{|c|}{ Unnecessary } \\
\hline & & $\frac{\grave{\Xi}}{\text { E }}$ & 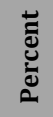 & हे & 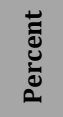 \\
\hline \multirow{24}{*}{ Clinical } & Fasting blood sugar & 22 & 96 & 1 & 4 \\
\hline & Blood sugar after two hours & 21 & 91 & 2 & 9 \\
\hline & Blood calcium levels & 23 & 100 & 0 & 0 \\
\hline & $\mathrm{CBC}$ & 23 & 100 & 0 & 0 \\
\hline & Phosphorus & 19 & 83 & 4 & 17 \\
\hline & Genetic testing & 23 & 100 & 0 & 0 \\
\hline & Type of epilepsy & 23 & 100 & 0 & 0 \\
\hline & Average blood pressure & 23 & 100 & 0 & 0 \\
\hline & Blood type & 22 & 96 & 1 & 4 \\
\hline & History of seizures & 23 & 100 & 0 & 0 \\
\hline & Family history of epilepsy & 23 & 100 & 0 & 0 \\
\hline & Pregnancy history & 17 & 73 & 6 & 27 \\
\hline & History of abortion & 17 & 73 & 6 & 27 \\
\hline & History of diabetes & 22 & 96 & 1 & 4 \\
\hline & History of heart failure & 21 & 91 & 2 & 9 \\
\hline & History of stroke & 23 & 100 & 0 & 0 \\
\hline & History of myocardial infarction & 23 & 100 & 0 & 0 \\
\hline & History of autism & 23 & 100 & 0 & 0 \\
\hline & Neurofibromatosis & 23 & 100 & 0 & 0 \\
\hline & History of brain tumour & 23 & 100 & 0 & 0 \\
\hline & History of head trauma & 23 & 100 & 0 & 0 \\
\hline & Severe stress & 23 & 100 & 0 & 0 \\
\hline & Anaemia & 20 & 87 & 3 & 13 \\
\hline & History of pulmonary insufficiency & 2 & 8.6 & 21 & 91.4 \\
\hline \multirow{9}{*}{$\begin{array}{c}\text { Clinical } \\
\text { Symptoms }\end{array}$} & Involuntary movements of muscles & 23 & 100 & 0 & 0 \\
\hline & Loss of consciousness & 23 & 100 & 0 & 0 \\
\hline & Chest muscle contraction & 23 & 100 & 0 & 0 \\
\hline & A loud shout & 19 & 83 & 4 & 17 \\
\hline & Staring at a point & 23 & 100 & 0 & 0 \\
\hline & Dyspnoea & 23 & 100 & 0 & 0 \\
\hline & Bitten tongue & 20 & 87 & 3 & 13 \\
\hline & Perpetual distress attacks & 23 & 100 & 0 & 0 \\
\hline & Vibration of the limbs & 23 & 100 & 0 & 0 \\
\hline
\end{tabular}

Clinical information with 23 elements had the largest number of elements. In this group, experts did not agree on data element of history of lung disease. In the demographic group, 11 elements were confirmed by the experts in which 4 elements (address, phone number, father's name and mother names) were not confirmed. In clinical symptoms (included 9 elements) all suggested elements were confirmed by experts. In medications and reminders and general recommendations all suggested items received approval.

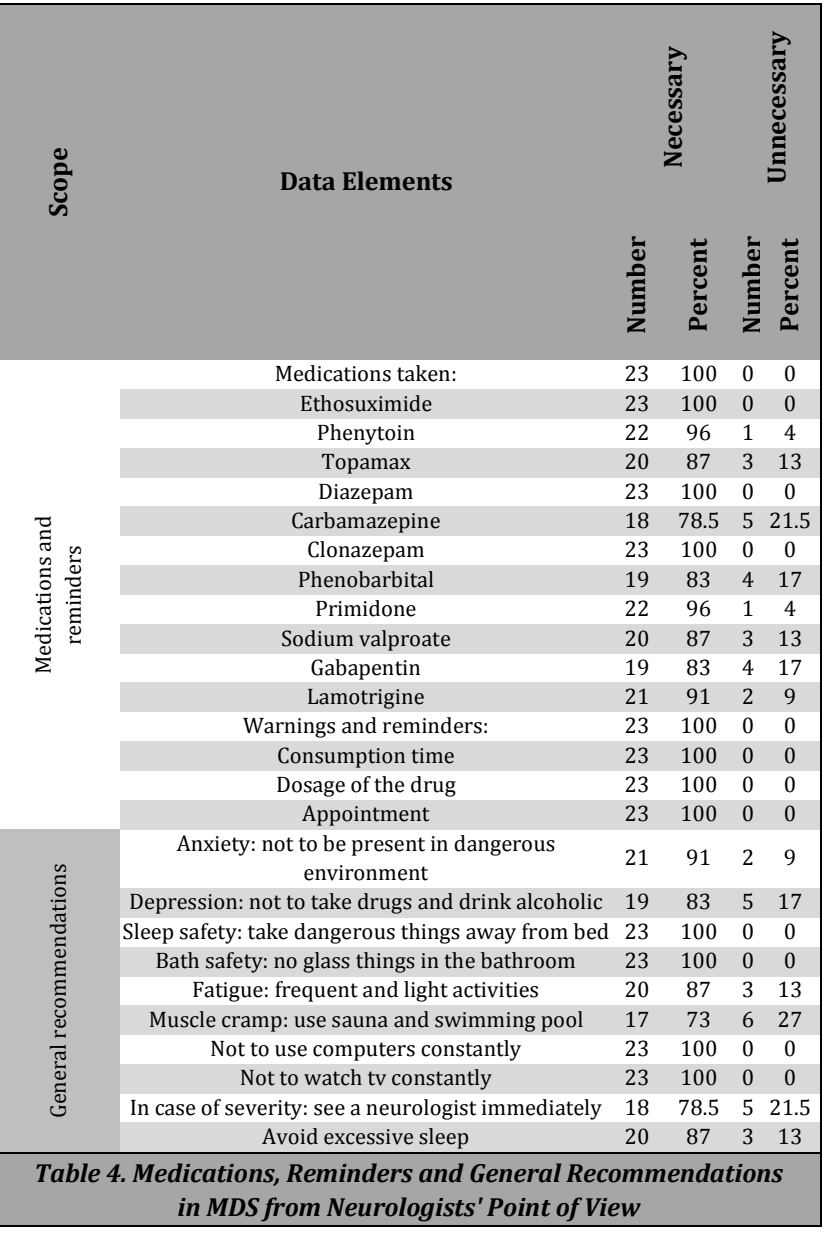

\section{DISCUSSION}

Early studies showed that self-care data for epileptic is not available; hence, it is necessary to design a set of minimum data as a tool to collect unified data elements.

In an investigation, in terms of designing of cataracts minimum data set, data was gathered by a number of surgeons. The purpose of this study was to make shared and solid cataract data. The intended data was mentioned in two parts; the first one was related to patients' demographic data: patients' name and last name, date of birth, gender, and second part includes patients' eye exam, eyesight condition and the treatment patients received. ${ }^{17}$ By comparing that study, it was realised that demographic data corresponds with this study.

A research by Moghbeli entitled "conceptual model of personal health record for autistic patients" considered necessary elements for electronic health record including demographic and clinical information. In demographic group, according to the opinion poll, while patients' fathers name, address and phone number were not a priority, their name and surname, father name, national code, age, gender, marital status, address, and phone number were determined as the minimum demographic data. ${ }^{18}$

Davey et al, in an investigation entitled "a proposed minimum data set for international primary care optometry: a modified Delphi study" illustrated minimum data set like patients' demographic information, their medical and family history and clinical trials, general recommendations, lifestyle, 
and examination results. ${ }^{19}$ In this study, all cases were also considered except patients' lifestyle and examination results.

Langarizadeh's research entitled "a minimum data set of laboratory reporting system for exchanging with electronic health record system in Iran" the MDS for demographic information included patients' name and surname, their father name, record number, date of birth, place of birth, age, gender, weight, geographical information, zip code, address, phone number, and educational level; ${ }^{20}$ while their name and surname, national code, gender, age, weight, occupation, education, citizenship, marital status, number of children were considered as minimum demographic data set. By comparing these two studies it was revealed that their father's name and record number, geographical information and ID number were not prioritised.

Although this study has been fulfilled with the help of 23 neurologists and it was a limit, we have to poll it again in a greater fulfillment. Using a standard data set, scientific and domestic ones seem necessary to produce, revise, develop and promote and familiarise beneficiaries of self-care software such as epileptics' self-care software. To do so, it is suggested to study present standards more for developing such a software.

\section{CONCLUSIONS}

This study showed that comprehensive and uniform data elements about Self-Care Training Software for epilepsy patients do not exist in Iran. Therefore, an MDS was developed for Self-Care Training Software for epilepsy in Iran. Minimum data set can be useful in designing Self-Care Training Software for those suffering from epilepsy towards integration of their fragmented records across continuum of the health care system in order to improve quality of shared patient care. Furthermore, it is concluded that designed data set can fulfill epileptics' needs and facilitate processes, promote their health and ease the financial burden of caring for patients with chronic illness.

Data sharing statement provided by the authors is available with the full text of this article at jemds.com.

Financial or other competing interests: None.

Disclosure forms provided by the authors are available with the full text of this article at jemds.com.

\section{REFERENCES}

[1] Beghi E. The epidemiology of epilepsy. Neuroepidemiology 2020;54(2):185-91.

[2] Ahammad N, Fathima T, Joseph P. Detection of epileptic seizure event and onset using EEG. Biomed Res Int 2014;2014(1):450573.

[3] Singh A, Trevick S. The epidemiology of global epilepsy. Neurol Clin 2016;34(4):837-47.

[4] Thurman DJ, Begley CE, Carpio A, et al. The primary prevention of epilepsy: a report of the prevention task force of the international league against epilepsy. Epilepsia 2018;59(5):905-14.
[5] Trinka E, Kwan P, Lee B, et al. Epilepsy in Asia: disease burden, management barriers and challenges. Epilepsia 2019;60(Suppl 1):7-21.

[6] Mansouri A, Singh SP, Sayood K. Online EEG seizure detection and localization. Algorithms 2019;12(176):118.

[7] Chapell R, Reston J, Snyder D, et al. Management of treatment-resistant epilepsy. Evid Rep Technol Assess (Summ) 2003;77:1-8.

[8] Lau-Walker M, Presky J, Webzell I, et al. Patients with alcohol-related liver disease--beliefs about their illness and factors that influence their self-management. J Adv Nur 2016;72(1):173-85.

[9] Karen M. Nutritional help guide concerns in rheumatoid arthritis. Arthritis Rheumatol 2017;7(1):3-11.

[10] Sakakibara BM, Ross E, Arthur G, et al. Using mobilehealth to connect women with cardiovascular disease and improve self-management. Telemed J E Health 2017;23(3):233-9.

[11] Sajatovic M, Johnson EK, Fraser RT, et al. Selfmanagement for adults with epilepsy: aggregate managing epilepsy well network findings on depressive symptoms. Epilepsia 2019;60(9):1921-31.

[12] Malekzadeh J, Amouzeshi Z, Mazloum R. The effect of teaching orem self - care model on nursing students communication performance in clinical setting. Modern Care Journal 2011;8(3):107-15.

[13] Beste LA, Harp BK, Blais RK, et al. Primary care providers report challenges to cirrhosis management and specialty care coordination. Dig Dis Sci 2015;60(9):2628-35.

[14] Reese JB, Somers TJ, Keefe FJ, et al. Pain and functioning of rheumatoid arthritis patients based on marital status: is a distressed marriage preferable to no marriage? J Pain 2010;11(10):958-64.

[15] Sheikhian MR, Bonab SM, Ahadi M, et al. Relationship between behavioral disorders and quality of life in patients with liver cirrhosis. Govaresh 2014;19(1):20-5.

[16] Sheikhtaheri A, Aliabadi A, Aval SS. The quality of health records used in the processing of lawsuit cases, a study in Zabol, Iran. International Journal of Ayurvedic Medicine 2018;9(2):79-82.

[17] Day AC, Donachie PHJ, Sparrow JM, et al. The royal college of ophthalmologists' national ophthalmology database study of cataract surgery: report 2, relationships of axial length with ocular copathology, preoperative visual acuity and posterior capsule rupture. Eye (Lond) 2015;29(12):1528-37.

[18] Moghbeli F, Adel T, Langarizadeh M, et al. A conceptual model of personal health record for autistic patients. Frontiers in Health Informatics 2019;8(1):18.

[19] Davey CJ, Slade SV, Shickle D. A proposed minimum data set for international primary care optometry: a modified Delphi study. Ophthalmic Physiol Opt 2017;37(4):428-39.

[20] Langarizadeh M, Gholinezhad M. A minimum data set of laboratory reporting system for exchanging with electronic health record system in Iran. Journal of Health Adminisrtation 2017;19(66):61-70. 